\title{
Relationship between Selected Risk Factors for Cardiovascular Diseases and the Quality of Life
}

\author{
Rita Nkechi Ativie*, Uzoma Emmanuella Onah \\ Department of Medical Rehabilitation, Faculty of Health Sciences and Technology, University of Nigeria, Enugu Campus, Enugu, Nigeria \\ Email: *rita.ativie@unn.edu.ng
}

How to cite this paper: Ativie, R.N. and Onah, U.E. (2019) Relationship between Selected Risk Factors for Cardiovascular Diseases and the Quality of Life. Open Journal of Therapy and Rehabilitation, 7, 106-119.

https://doi.org/10.4236/ojtr.2019.73007

Received: April 15, 2019

Accepted: June 29, 2019

Published: July 2, 2019

Copyright $\odot 2019$ by author(s) and Scientific Research Publishing Inc. This work is licensed under the Creative Commons Attribution International License (CC BY 4.0).

http://creativecommons.org/licenses/by/4.0/

\begin{abstract}
The ageing population is more predisposed to chronic diseases and functional disabilities with an increased level of dependence. The delivery of adequate health care services to the ageing population requires enquires into their quality of life. This cross-sectional study therefore investigated the relationship between some selected risk factors for cardiovascular diseases (CVD) and the quality of life of aging adults. Using a convenient sampling technique, one hundred and forty six (146) adults of ages 50 years and above from varying locations within the Metropolis of Enugu State, Nigeria were recruited. The parameters obtained were participants' blood pressure, height, body weight, waist circumference and blood sugar level. Health-related quality of life was assessed using the WHO-QOL BREF and physical activity level was assessed with the IPAQ. Data were summarized using descriptive statistics of frequency and percentage while the statistical measures of relationship (Pearson's moment correlation and spearman rho correlation) were used to calculate the relationship between obtained data. The result revealed a positive relationship between waist circumference (obesity indicator) and the environment domain of quality of life measure $(r=0.227, p=0.006)$. Surprisingly, no relationship was found between obesity indicators (waist circumference and BMI) and physical/psychological health status. The result also found a positive relationship between physical activity levels and quality of life; a weak negative relationship between casual blood sugar levels and the social relationship domains of quality of life and a weak negative relationship was also observed between age and physical activity and psychological health. Therefore, reduced physical activity level influences a poor quality of life. We recommend physical activity participation among the older population, as well as detailed similar studies for higher degree of certainty.
\end{abstract}

\section{Keywords}

Cardiovascular Disease, Quality of Life, Risk Factors, Ageing 


\section{Introduction}

Being the world's leading cause of death, cardiovascular diseases (CVDs) are known to pose huge threats to low and middle income nations alike [1]. This has prompted divergent opinions; specifically from the World Health Organization (2006) that classifies its risk factors into two; individual and environmental risk factors. The individual risk factors of CVDs are: age, sex, formal education level, heredity and those associated with lifestyle (tobacco use, diet, and sedentary lifestyle). Environmental risk factors reportedly consist of urbanization and socioeconomic, cultural, and environmental conditions [2].

Common examples of CVDs such as Peripheral artery disease, coronary artery disease, arrhythmia, stroke, atherosclerosis, hypertension and congestive cardiac failure have been suggested to be among the leading diseases causing disability adjusted life [3], and are also the most important cause of death across all ages [1] [4]. This thus makes CVDs outstanding in its role at outranking any other cause of mortality in humans, especially those above the age 65 [4].

The ability of risk factors of CVDs to contribute to human quality of life is undeniable with such level of contribution as comparable to those of CVD diagnosed individuals [5]. Different people perceive quality of life (QoL) differently, especially as contextualizing it as a balance between the body and mind [5]; having very strong support in illness [3]; and effectively coping with strategies. Howbeit, health has been seen to have the highest influence on the quality of life of humans [6], and is not only the absence of disease but the state of wellness and all round well-being; including physically, mentally, socially and psychologically [3]. Quality of life is also seen as general contentment with life or its components in relation to fulfilment of goals and aspirations, especially in standards and in concerns.

The concept of QoL is multifaceted, and could be seen to be subjective, objective and/or relational [3] [5]. Over time, health-related QoL includes such factors as psychological, physical, and social functioning related to well-being [6]. QoL assessment is therefore important for promotion of independence (especially given the high prevalence of chronic conditions in older age, and studies targeted towards the structuring of policies aimed at the elderly population [3]. For people at risk of developing cardiovascular diseases, QoL is of both public health and clinical research concerns in showcasing the definition of health according to World Health Organization (WHO) as a "complete state of physical, mental and social wellbeing, and not merely the absence of disease or infirmity". QoL outcomes can help select therapeutic options and create awareness of the benefits of medical treatment to individuals particularly if side effects of drugs may impair their life satisfaction [7].

The ageing population will determine health in the next 25 years [8]. It is therefore important to direct efforts towards managing chronic diseases and promoting optimal function. Planning and delivery of health care services to aging individuals would require enquires into their quality of life and associated 
risk factors [3]. Hence, this study was designed to investigate the burden of cardiovascular disease risk factors on the quality of life of the adults in the selected areas of Enugu metropolis.

\section{Aim of Study}

This study aimed at enquiring into the relationship between selected risk factors for cardiovascular diseases and the quality of life of study population of adults in Enugu metropolis, Enugu state, Nigeria. Specifically, it was aimed at determining the relationship between age, obesity and Physical activity levels with quality of life. It also ascertained the existing relationship between impaired blood glucose levels/diabetes mellitus and quality of life. The relationship between such lifestyle attributes as alcohol consumption and cigarette smoking (tobacco use) and quality of life was also investigated

\section{Methodology}

\subsection{Research Design}

This study adopted the cross-sectional design approach to investigate the burden of cardiovascular disease risk factors on the quality of life of the adults in the selected areas in Enugu metropolis.

\subsection{Study Location}

Study was conducted at the Department of Medical Rehabilitation, Faculty of Health Science and Technology, University of Nigeria, Enugu Campus (UNEC). Areas close to the location of study were conveniently selected for data collection for the study. They include Little Sisters of the Poor, Home for the Elderly, Uwani Enugu; the Shuttle Park of the University of Nigeria Enugu Campus; Nnaji Nwede street, Igbariam street, Obiomia street and mayor market.

\subsection{Duration of Study}

Data collection was field based and lasted a total of 5 months, spanning between the months of February 2018 and June 2018.

\subsection{Study Population}

This research was conducted on adults who are 50 years or older, residing in Enugu metropolis.

\subsection{Sample and Sampling Technique}

Study adopted a convenience sampling technique, considering it appropriate because participants were recruited based on their availability and willingness to participate.

\subsection{Sample Size Calculation}

Using a power analysis to detect a relationship at a correlation coefficient of 0.2 , 
sample size was calculated as 153 at minimum, with a power of 0.8 and 0.05 level of test significance. However, 168 participants were recruited for this study while a total of 146 completed the study.

\subsection{Selection Criteria}

Study participants were drafted based on the following criteria.

\subsection{Inclusion Criteria}

1) Only participants who were 50 years or older.

2) Only subjects who were willing to participate in the study were recruited.

\subsection{Exclusion Criteria}

1) Participants aged 49 and below at the time of the data collection.

2) Participants with cognitive or any related impairments that could affect the assessment of the required variables.

\subsection{Instrument for Data Collection}

In the course of data collection, study used the following instruments;

1) Sphygmomanometer (Omrion, M2): A digital type with air bag for taking blood pressure.

2) Stadiometer (Aaron 226 USA): A measuring scale for height calibrated in centimetres used to measure the height of the participants.

3) Weighing scale (Harson China): A bathroom scale used to measure weight in $\mathrm{kg}$.

4) Tape measure: An inelastic measuring tape which is calibrated in centimetres on one side and inches on the other side which was used to measure the waist circumference.

5) Glucose meter: For blood glucose measurement and monitoring.

6) Sterile tips: This was used to prick the participant's finger to obtain a drop of blood for use on the glucose meter.

7) Test strip: This was used to collect blood sample $(0.5 \mu \mathrm{l})$ and inserted in the glucose meter for analysis.

8) Cotton wool: This was used to clean the area of the finger to be pricked.

9) Methylated spirit: This was used to sterilize the area of the finger to be pricked.

10) Latex hand gloves: This was worn by the researcher.

11) Questionnaire:

a) WHO-QOL BREF [3] this is an instrument for the measurement of various aspects of health (quality of life) drafted by World Health Organization (WHO) in collaboration with 15 centres around the world. The instrument was developed cross-culturally, using health care providers, administrators and legislators; Thus, making it effective and reliable. It was structured to assess four major areas of participants' life; physical, psychological, social relationships and environment. 
b) International Physical Activity Questionnaire (IPAQ) short version was used in the measurement of physical activity. This questionnaire asked questions on three specific types of activities; walking, moderate-intensity activities, and vigorous-intensity activities.

\subsection{Limitation of Study}

Study was majorly limited by the non-definitive response(s) of participants in some raised questions in the questionnaire. Also, the low number of respondents for sample size lowered the right to generalize the results from findings. Again, study relied on self-report from respondents that may cause over estimation or under estimation beyond researcher's control.

\subsection{Ethical Considerations}

1) Ethical approval was obtained from University of Nigeria Health Research Ethics Committee.

2) Informed consent was obtained from participants, after giving clear information of the procedure and the purpose of the research.

\section{Procedure for Data Collection}

\subsection{Measuring Participant's Height}

Participants were first instructed to stand barefooted on the platform of the height scale with feet together, the back against the height scale's stand and the eye looking forward. The height was measured as the distance from the height scale platform to the vertex of the head. The height was read off and recorded to the nearest 1.0 the centimetres.

\subsection{Measuring the Participant's Weight}

Weighing scale was adjusted to zero mark. Each participant was instructed to wear light clothing then stood barefooted and straight on the weighing scale while looking straight ahead with hands by the side. The body weight was read off to the nearest 1.0 kilogram.

\subsection{Obtaining Questionnaire Data}

This was divided into sections. First, we followed the WHO recommended steps to access risk factors for non-communicable diseases in one section, and the other section assessed tobacco and alcohol lifestyle. Next, Section B was the IPAQ questionnaire (short version) which was used to access for the physical activity. The minutes spent every week on each type of activity was computed separately by multiplying the duration and frequency of activity [9] [10]. A continuous activity score was then calculated by multiplying selected metabolic equivalent (MET) value and weekly minutes of activity, therefore expressing physical activity as MET min per week [10]. Subjects were then divided into low, moderates and high levels of physical activity on basis of their total physical ac- 
tivity (MET-min/week) and frequency of activities [10]. MET values and the levels of physical activity were then calculated in accordance with the guidelines for data processing and analysis of the IPAQ [10]. Here, Criterion validity had a median of about 0.30 , which was comparable to most other self-report validation studies [11]. Finally was Section C, where the WHO QOL BREF questionnaire was administered to the participants. It is divided into four categories; Physical: pain and discomfort, energy and fatigue, sleep and rest, mobility, daily life activities, undergoing medication or other treatment, work capacity. Psychological: positive sentiments; thinking, learning, memory and concentration; self-esteem; body image and appearance; negative sentiments; spirituality/religion/ personal beliefs. Social relations: personal relations, social support, sexual activity. Environment: physical safety and protection, environment in the home, financial resources, availability and quality of social and health care, opportunities for acquiring new information and abilities, participation in recreation/leisure opportunities, physical environment, such as level of pollution, noise, traffic, climate and transport. Guidelines in the literature were followed for calculating the scores [3].

\subsection{Obtaining Blood Pressure}

Participants' blood pressures were checked in relaxed, sitting and resting (for a few minutes) states. The right arm of the participant was placed on the table with the palm facing upward. Clothing on the arm was removed and the appropriate cuff size for the participant was used. The cuff was positioned above the elbow aligning the mark ART on the cuff with the brachial artery. The cuff was wrapped snugly onto the arm and securely fastened with the Velcro. The lower edge of the cuff was placed 1.2 to $2.5 \mathrm{~cm}$ above the inner side of the elbow joint and the level of the cuff was at the same level as the heart during measurement. Blood pressure was recorded as high when it was above $140 \mathrm{mmHg}$ for systolic blood pressure and $90 \mathrm{mmHg}$ for diastolic blood pressure or when they reported to be on medications for hypertension.

\subsection{Obtaining Blood Sugar Level}

This was taken during the morning hours, following overnight fast. The fasting blood sugar of the participant was taken where possible and the time the participant ate compared with the time the test was taken was recorded. Fasting glucose was recorded as normal when it was between $70 \mathrm{~mm} / \mathrm{dl}$ and $100 \mathrm{~mm} / \mathrm{dl}$, impaired at $101 \mathrm{~m} / \mathrm{dl}-125 \mathrm{~mm} / \mathrm{dl}$ and diabetic $>126 \mathrm{~mm} / \mathrm{dl}$. For random sugar level ( 2 - 3 hours post meal) $120 \mathrm{~mm} / \mathrm{dl}-140 \mathrm{~mm} / \mathrm{dl}$; normal, $141 \mathrm{~mm} / \mathrm{dl}-160$ $\mathrm{mm} / \mathrm{dl}$; impaired and $>200 \mathrm{~mm} / \mathrm{dl}$; diabetic. Those taken within 1 hour post meal, $170 \mathrm{~mm} / \mathrm{dl}-200 \mathrm{~mm} / \mathrm{dl}$; normal, $190 \mathrm{~mm} / \mathrm{dl}-230 \mathrm{~mm} / \mathrm{dl}$; impaired and >230 $\mathrm{mm} / \mathrm{dl}$ as diabetic. It was also recorded as diabetic for those who were taking medications for diabetes. The area to be pricked was sterilized with methylated spirit and the sharps were well disposed after use. Test was taken by the researcher 
with gloves on to prevent infection.

\subsection{Measuring Waist Circumference}

The inferior margin (lowest point) of the last rib and the crest of the ilium (top of the hip bone) was located with a fine pen. The midpoint was then found with a tape measure and marked. The tension tape was applied over the marked midpoint and the participant was asked to wrap it round themselves. The participant was then asked to stand with their feet together, with their arms at their side and the palms of their hands faced inwards. They were also asked to breathe out gently. The waist circumference was measured and read at the level of the tape to the nearest $0.1 \mathrm{~cm} \mathrm{[12].}$

\subsection{Obtaining the Body Mass Index}

This was calculated from the individual's height and weight, using the formula;

$$
\frac{\text { weight }}{\text { height }^{2}}
$$

\subsection{Method of Data Analysis}

Obtained data was presented with descriptive statistics of frequencies and percentages, pie chart, mean and standard deviation. Correlation analysis of Spearman was used to explore association between behavioural characteristics, blood pressure levels and the various domains of quality of life. Pearson's correlate was used to explore associations between indices of obesity, physical activity levels and various domains of quality of life. Alpha level was set at $\mathrm{p}<0.05$.

\section{Results}

This section presents a detailed report on the outcome of obtained data based on the objectives of the study. Presented data consists of quantitative reports from sampled respondents who were involved in the study; following sorting and statistical analysis. Here, descriptive statistics was used to analyse demographic data, with frequency distribution used to present different variables. Figure 1 shows of the gender distribution of participants. It revealed that $88(60.3 \%)$ of the participants were males with 58 (39.7\%) being females. Figure 2 shows participants' BMI distribution frequency. It reveals that of the 146 participants, 63 (43.2\%) had normal weight, 47 (32.2\%) were overweight and 36 (24.7\%) were obese. Figure 3 reveals that out of 146 respondents, 83 (56.8\%) had low physical activity levels, 48 (32.9\%) had moderate physical activity levels and 15 (10.3\%) had high physical activity levels. Figure 4, shows that out of 146 participants, 90 (61.6\%) last drank alcohol 30 days ago or more (from the time the data was taken), $30(20.5 \%)$ drank less than two bottles of alcohol daily and 20 (17.8\%) drank at least two bottles, daily while Figure 5 shows that 123 (84\%) never smoked, 11 (7.5\%) had ever smoked and $12(8.2 \%)$ were current smokers. Figure 6 shows the frequency of blood pressure among the participants. It reveals that of the 146 


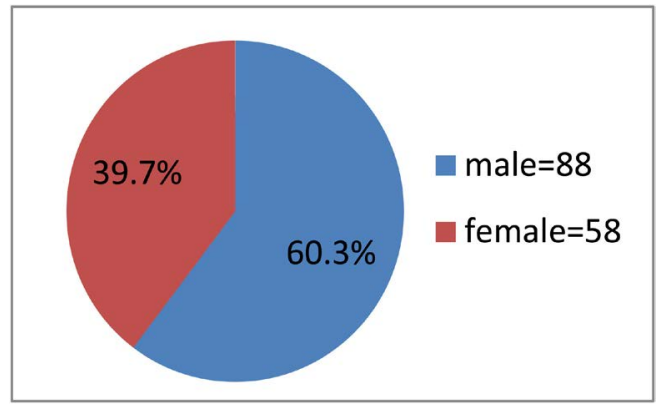

Figure 1. Gender distribution of respondents.

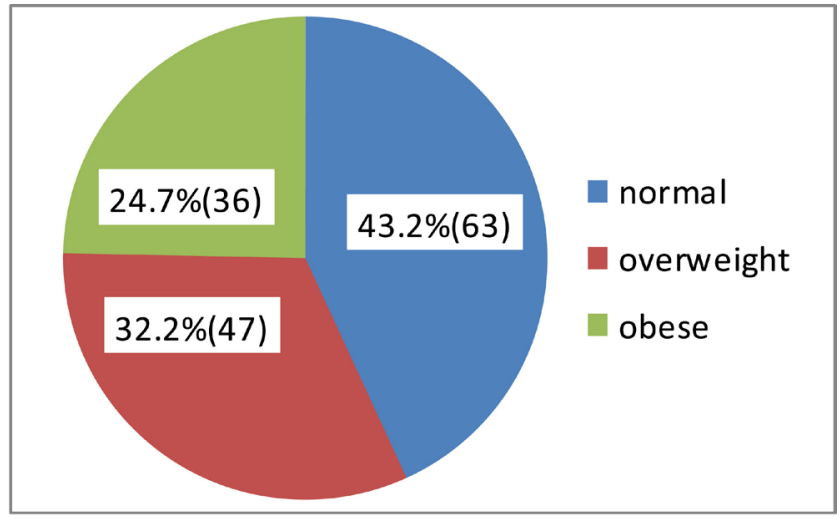

Figure 2. BMI distribution of respondents.

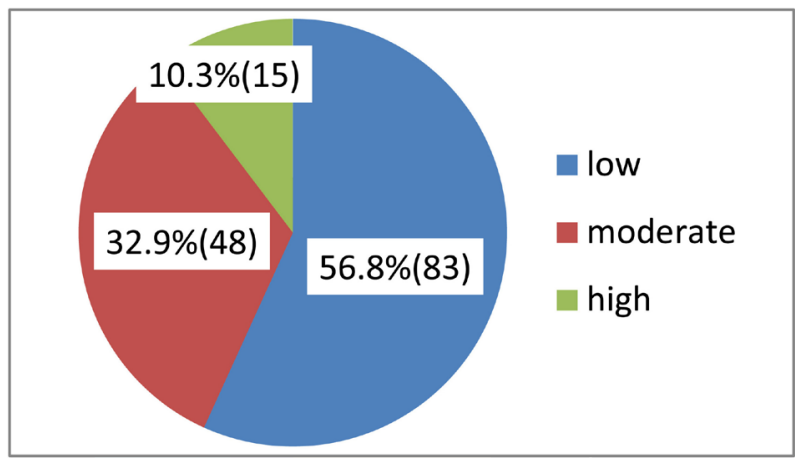

Figure 3. Showing levels of physical activity distribution of respondents.

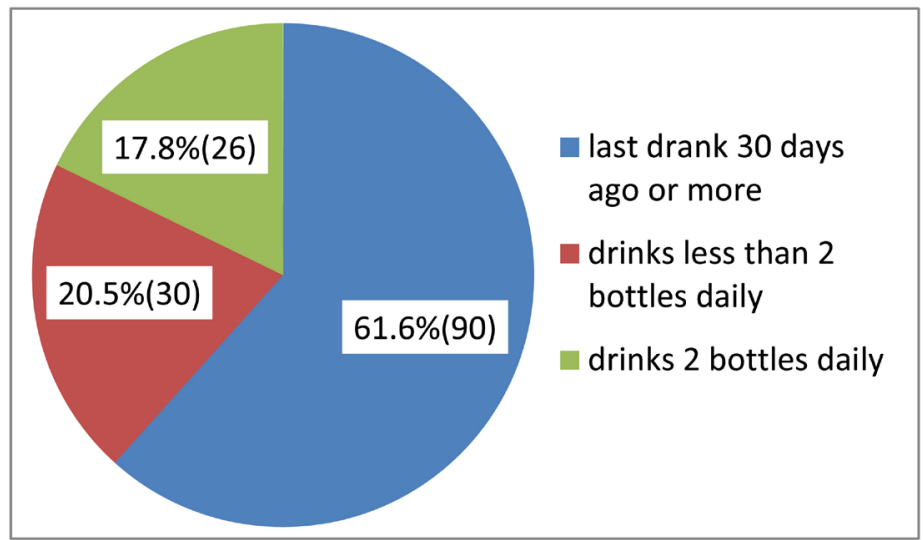

Figure 4. Alcohol consumption distribution of respondents. 
participants, $82(56.7 \%)$ had normal blood pressure and 64 (42.8\%) had high blood pressure. Table 1 compares average systolic and diastolic blood pressures of participants with cardiovascular health indicators as BMI and physical activity levels. Results are presented as Mean \pm Standard Deviation. Table 2 shows there was a significant weak positive relationship between WC and the environment

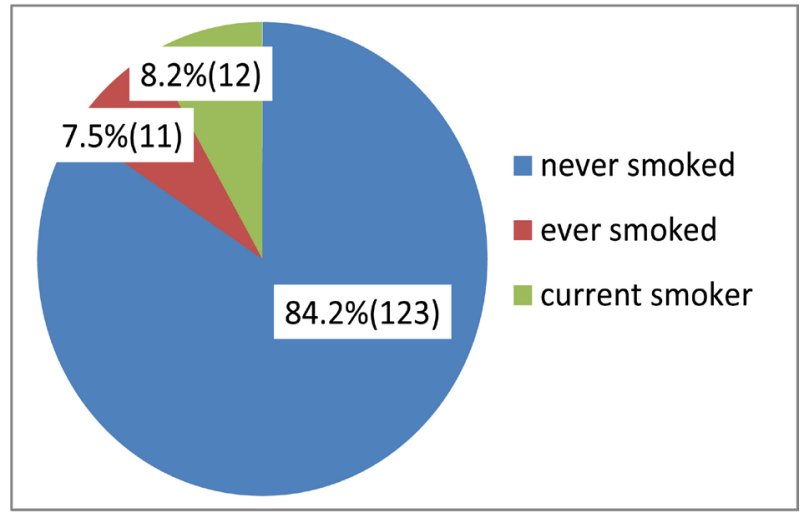

Figure 5. Cigarette smoking (tobacco use) distribution of respondents.

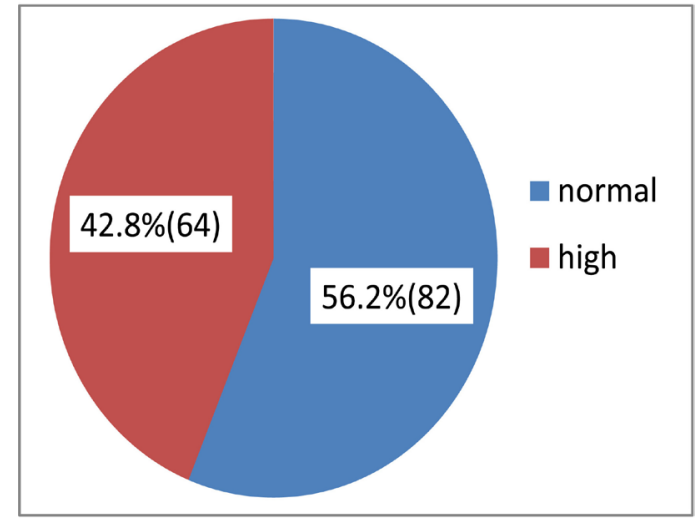

Figure 6. Blood pressure distribution of respondents.

Table 1. Summary of average values of obtained variables.

\begin{tabular}{cc}
\hline Variables & Mean \pm SD \\
Age & $63.84 \pm 10.673$ \\
Systolic BP $(\mathrm{mmHg})$ & $133.91 \pm 23.247$ \\
Diastolic BP $(\mathrm{mmHg})$ & $82.62 \pm 15.682$ \\
waist circumference $(\mathrm{cm})$ & $95.2534 \pm 13.61532$ \\
BMI $\left(\mathrm{kg} / \mathrm{m}^{2}\right)$ & $26.444 \pm 4.9871$ \\
Physical health Domain & $14.08 \pm 2.869$ \\
Psychological health Domain & $13.84 \pm 2.158$ \\
Social relationships Domain & $13.81 \pm 2.486$ \\
Environment Domain & $14.07 \pm 1.874$ \\
Physical activity level (MET·min.day) & $1249.71 \pm 1816.730$ \\
\hline
\end{tabular}


Table 2. Showing correlation between indices of obesity (BMI, WC), physical activity levels and quality of life.

\begin{tabular}{ccccccc}
\hline & $\begin{array}{c}\text { Physical health } \\
\text { domain }\end{array}$ & $\begin{array}{c}\text { Psychological } \\
\text { health domain }\end{array}$ & $\begin{array}{c}\text { Social relationships } \\
\text { domain }\end{array}$ & $\begin{array}{c}\text { Environment } \\
\text { domain }\end{array}$ & $\begin{array}{c}\text { BMI } \\
\mathbf{k g} / \mathrm{m}^{2}\end{array} \quad \begin{array}{c}\text { WC } \\
\mathrm{cm}\end{array}$ levels \\
\hline BMI & $\mathrm{r}=0.068$ & $\mathrm{r}=0.006$ & $\mathrm{r}=-0.16$ & $\mathrm{r}=0.158$ & 1 & \\
& $\mathrm{p}=0.414$ & $\mathrm{p}=0.943$ & $\mathrm{p}=0.852$ & $\mathrm{p}=0.056$ & & \\
WC & $\mathrm{r}=0.049$ & $\mathrm{r}=-0.010$ & $\mathrm{r}=-0.038$ & $\mathrm{r}=0.227^{* *}$ & $0.757^{* *}$ & 1 \\
& $\mathrm{p}=0.556$ & $\mathrm{p}=0.904$ & $\mathrm{p}=0.651$ & $\mathrm{p}=0.006$ & 0.001 & \\
PA & $\mathrm{r}=0.365^{* *}$ & $\mathrm{r}=0.182^{*}$ & $\mathrm{r}=0.219^{* *}$ & $\mathrm{r}=0.188^{*}$ & & \\
levels & $\mathrm{p}<0.001$ & $\mathrm{p}=0.028$ & $\mathrm{p}=0.008$ & $\mathrm{p}=0.023$ & & 1 \\
\hline
\end{tabular}

Keys: BMI: Body Mass Index, WC: Waist Circumference, PA; Physical Activity. ${ }^{*}$ Correlation is significant at the 0.01 level, ${ }^{*}$ Correlation is significant at the 0.05 level.

domain of quality of life $(\mathrm{r}=-0.227 ; \mathrm{p}=0.006)$. There was no significant relationship between BMI and physical $(\mathrm{p}=0.414)$, psychological $(\mathrm{p}=0.943)$, social relationships $(p=0.852)$ and environment $(p=0.056)$ domains. However, there was a significant strong positive relationship between WC and BMI $(r=0.757 ; \mathrm{p}$ $<0.001)$.

\section{Discussion}

With available studies suggesting several risk factors in the pathogenesis of cardiovascular diseases, often than not, most reports have implicated Obesity, excessive alcohol consumption, tobacco intake, diabetes mellitus, physical inactivity and high blood pressure as key issues.

Current study investigated the relationships between cardiovascular disease risk factors (measured by; physical activity level, alcohol consumption, tobacco use, impaired glucose levels/diabetes, age, high blood pressure and obesity) and quality of life among adults of 50+ years who are resident in Enugu metropolis. A total of 146 persons ( 88 males and 58 females) participated in this study, with majority being adults $(51 ; 34.9 \%)$ of between the ages of 50 and 59 years. Of the sampled participants, $13 \%$ (19) were civil servants, $15.8 \%$ (23) business owners, $31.5 \%$ (58) labourers and $39.7 \%$ (58) retired. Majority of the participants were married (103; 70.5\%). About $43.2 \%$ (63) were of normal weight while $32.2 \%$ (47) and $24.7 \%$ (36) of the participants were observed to be overweight and obese respectively.

From the study, a large majority of the participants had normal blood glucose level (112; 76.7\%). About 61.6\% (90) of the participants reported to have abstained from alcohol consumption for at least 30 days, 20.5\% (30) drank less than 2 standard drinks daily, while $17.8 \%$ (20) drank at least two standard drinks daily. Almost all participants (123; 84\%) had never smoked, with about 56.8\% (83) of them being of low physical activity level, and about $32.9 \%$ (48) and 10.3\% (15) being of moderate and high PA level respectively. High blood pressure was found among $42.8 \%$ (64) while $56.7 \%$ (82) had normal blood pressure levels. 
Cardiovascular disease risk prevalence in this study was relatively low. Quality of life scores on the 4 to 20 scale, for the physical health domain ranged mostly between 10 to 14 and 15 to 19 , that is, 54 (37\%) and 64 (43.8\%) respectively. For the psychological domain, the same pattern was seen but a higher frequency of scores between 10 to14 (82; 56.2\%). Social relationships and environment domains both had their highest frequencies in the 10 to 14 score range with 56 (38.4\%) and 74 (50.7\%) respectively. These values are closely related to other studies [12].

Outcome of correlative report from this study showed a positive relationship between waist circumference and the environment domain of quality of life $(r=$ $0.227, \mathrm{p}=0.006)$. This means that an increase in abdominal obesity may influence the environmental aspect of quality of life. This result was observed to be inconsistent with those of Martinelli et al. (2008) [13]. Also, BMI showed no significant relationship with social and environment domains (Table 2) in an inconsistent fashion with study done by Martinelli et al. (2008) who found a relationship between obesity measured by BMI and the physical health domain, he also found no relationship between obesity and the other domains of quality of life although a different quality of life questionnaire was used. Also; surprisingly, no relationship was found between the obesity indices and physical and psychological health domains. An explanation may be that most studies demonstrating a relationship between quality of life and obesity were conducted with North American and European populations. The few studies exploring this relationship in developing countries show contradictory results regarding the association between obesity and impaired quality of life [14]. This inconsistency may be explained by the cultural and ethnic differences [15]. Also, a large proportion of the sample populations of this study (31.5\%) were labourers who may not view physical health as a challenge.

Again, Results from current study proved positive for the correlated relationship between physical activity levels and all domains of quality of life, (physical: $r$ $=0.365, \mathrm{p}<0.001$; psychological: $\mathrm{r}=0.182, \mathrm{p}=0.028$; social: $\mathrm{r}=0.219, \mathrm{p}=0.008$; environment: $r=0.188, p=0.023)$ with a stronger relationship in the physical domain $(r \approx 0.4)$. This implies that an increase in physical activity levels will influence an improvement in the quality of life of an individual. This finding is consistent with several studies [16]. Regular physical activity has been linked to reduction of coronary artery disease and other chronic diseases, such as diabetes mellitus, osteoporosis, obesity, depression, and cancer of the breast and colon [16]. It also reduces the risk of several co-morbidities especially; arthritis, hence the stronger relationship seen with the physical domain.

On the relationship between impaired fasting blood glucose/diabetes and quality of life, this study showed a weak negative relationship between casual blood sugar levels and the social relationships domain of quality of life $(r=$ $-0.175, \mathrm{p}=0.035)$. This means that an increase in glucose levels will likely influence a poorer quality of life in the aspect of social relationships. This finding 
was not consistent with the study done by Noguchi (2005) [10] but is consistent with other studies done to show the impact of diabetes mellitus on quality of life [12]. No relationship was however, found between casual blood glucose levels and the other domains of quality of life (physical: $r=0.008, p=0.922$; psychological: $r=-0.087, p=0.294$; environment: $r=-0.175, p=0.646$ ). This may be due to the fact that a large number of the sample population (112), had normal glucose levels and thus it was difficult to detect a relationship.

Again, this study showed a weak negative relationship between age and physical and psychological health domain $(\mathrm{r}=-0.310, \mathrm{p}<0.001 ; \mathrm{r}=-0.217, \mathrm{p}=0.008)$. This implies that an increase in age will influence a poorer quality of life in the physical and psychological aspects. This finding was observed to be consistent with a study done by Moran (2003), but not consistent with the study done by Noguchi (2005) [10] who found no relationship between increased ages and quality of life, except a measure of protective effects on the environment domain. Similarly, Moran (2003) in their review found that good quality of life was associated with older ages, although they noted the influence of cultural differences and the difficulty of older individuals to understand the concept of quality of life. Physical and psychological health was influenced negatively by increased age, possibly because of declining physical and mental capabilities which are associated with aging [10] [11]. A negative relationship of age with social relationships was also seen $(\mathrm{r}=-0.125)$, although this relationship was insignificant $(\mathrm{p}=$ 0.133 ), it could be due to isolation as a result of death of contemporaries and break down of extended families, which was a concern for some of the participants of this study. No relationship was found between environment domain of quality of life and age $(\mathrm{r}=-0.055, \mathrm{p}=0.511)$. This could mean that most of the older participants were more concerned with physical health as age also leads to increase in overweight and obesity [12].

For the relationship between alcohol consumption and quality of life study showed a weak positive relationship between alcohol consumption and the physical and psychological health domain (Table 2). This means that an increase in alcohol consumption would influence a better quality of life in the physical and psychological aspects. Surprisingly, it was consistent with the findings in another study done by Flegal et al. (2008) in Spain. The prospective cohort study carried out by Ortola. $\mathrm{R}$ and his team showed that better quality of life scores were associated with heavy and moderate drinking. An inverse association was found between alcohol consumption and quality of life in a study done by Flegal (2008) among young adults in Taiwan. This implies that alcohol consumption may influence quality of life negatively, but changes the direction of association as age increases due to change in perception of health as age increases. It is important to note however that poorer quality of life among individuals at risk of cardiovascular diseases is better associated in the presence of co-morbidities [16]. A positive relationship was observed between alcohol consumption and the social and environment domain, $(r=0.117, \mathrm{p}=0.160 ; \mathrm{r}=0.117, \mathrm{p}=0.160)$ al- 
though not significant. This finding is therefore not sufficient to infer an actual influence of alcohol consumption on those aspects of quality of life.

This study also showed that there was no relationship between tobacco use and quality of life in all the domains assessed (physical: $r=0.008, p=0.923$; psychological: $\mathrm{r}=-0.027, \mathrm{p}=0.747$; social: $\mathrm{r}=-0.017, \mathrm{p}=0.841$; environment: $\mathrm{r}$ $=-0.066, \mathrm{p}=0.430)$. This finding is inconsistent with several studies. This may be due to the low prevalence of tobacco use in this study population and in $\mathrm{Ni}$ geria when compared to the prevalence in the countries where those studies were carried out. It is expected that tobacco will have a negative association with quality of life, but for a younger population group, as bias of survival of tobacco users are seen in ages above 64 [12].

This study also revealed a weak negative relationship between blood pressure and quality of life in the physical health domain $(\mathrm{r}=-0.183, \mathrm{p}=0.027)$. This means that an increase in blood pressure levels will influence a decrease in quality of life with respect to physical health. This finding was consistent with those in the study done by Anrig (2003) who found that blood pressure was associated with lower scores of quality of life. However, no relationship was found between blood pressure and quality of life (psychological: $\mathrm{r}=-0.071, \mathrm{p}=0.394$; social: $\mathrm{r}=$ $-0.0069, \mathrm{p}=0.407$; environment: $\mathrm{r}=-0.005, \mathrm{p}=0.430$ ).

\section{Conclusion}

Current study was undertaken to inquire into the underlying relationship between selected risk factors for cardiovascular diseases (CVD) and quality of life. Upon careful investigation, this study observed that; a relatively healthy quality of life in adults above 50 years with Physical activity has the highest level of relationship with quality of life. This study observed no relationship between tobacco use and BMI with quality of life unlike alcohol consumption. Blood glucose level and high blood pressure were also shown to have positive relationship with social domain and physical domain of quality of life respectively.

\section{Recommendations}

Age specific and multi-dimensional quality of life measure for evaluating the outcomes of health and social care in older populations is highly recommended. Also, physical activity should be emphasized at clinics during care the management of the older population to improve their quality of life. There is need for longer term studies (with larger sample size) as findings from current study were not based on cause and effect or on longitudinal observational study. Interventional studies are also strongly encouraged to provide more definite results.

\section{Conflicts of Interest}

The authors declare no conflicts of interest regarding the publication of this paper. 


\section{References}

[1] World Health Organization (WHO) (2011) Global Atlas on Cardiovascular Disease Prevention and Control. World Health Organization, Geneva.

[2] Omari, A. and Caterson, I.D. (2007) Essentials of Human Nutrition. 3rd Edition, Oxford University Press Inc., New York.

[3] WHO (2016) Obesity Preventing and Managing the Global Epidemic. Report of a WHO Consultation on Obesity.

[4] Anrig, C.D.C. (2003) The Obese Child Dynamic Chiropractice. International Journal of Obesity, 21, 2731.

[5] Saris, W.H.M. (1996) Physical Activity and Body Weight Regulation. In: Bouchard, C. and Bray, G.A., Eds., Regulation of Body Weight. Biological and Behavioural Mechanism Chichester, Willey, Hoboken, 135-147.

[6] Mc Cauley, K.A. (2002) Intensive Lifestyle Changes Are Necessary to Improve Insulin Sensitivity. Diabetes Care, 25, 445-459. https://doi.org/10.2337/diacare.25.3.445

[7] Parson, T.J., Power, C., Logan, S. and Summerbell, C.D. (1999) Childhood Predictors of Adult Obesity. International Journal of Obesity, 23, S1-S107.

[8] Flegal, K.M., Harlan, W.R. and Landis, J.R. (2008) A Secular Trends in Body Mass Index and Skinfold Thickness with Socioeconomic Factors in Young Adult Men. American Journal of Clinical Nutrition, 48, 544-551. https://doi.org/10.1093/ajen/48.3.544

[9] Beilin, B.V., Dunbar, L.J. and Kevan, D. (2004) Changes in Health-Related Behaviours and Cardiovascular Risk Factors in Young Adults: Associations with Living with a Partner. Preventive Medicine, 39, 722-730. https://doi.org/10.1016/j.ypmed.2004.02.038

[10] Noguchi, H. (2005) The Relationship between Serum Transaminase Activities and Fatty Lives in Children with Simple Obesity. Acta Paediatrica Japonica, 37, 621-265. https://doi.org/10.1111/j.1442-200X.1995.tb03389.x

[11] Edmunds, L.E. and Waters, E.J. (2001) Evidence Based Paediatrics: Evidence Based Management of Childhood Obesity. British Medical Journal, 323, 916-919. https://doi.org/10.1136/bmj.323.7318.916

[12] Benkeser, R.M., Biritwum, R. and Hill, A.G. (2012) Prevalence of Overweight and Obesity and Perception of Healthy and Desirable Body Size in Urban Ghanaian Women. Ghana Medical Journal, 46, 66-75.

[13] Ghrayeb, F.A.W., et al. (2013) Prevalence of Overweight and Obesity among Adolescents in Tarqumia, Palestine. Canadian Journal of Basic and Applied Sciences, 1 , 49-57.

[14] Amira, C.O., Sokunbi, D.O.B., Dolapo, D. and Sokunbi, A. (2011) Prevalence of Obesity, Overweight and Proteinuria in an Urban Community in South West Nigeria. Nigerian Medical Journal, 52, 110-113.

[15] Rahnama, R., Rampal, L., SannLye, M., Sidik, S.M. and Abedi, P. (2017) Diet Knowledge and Behaviours Related to Prevention of Obesity among Students Aged 11 to 15 Years in Shiraz, Iran. Iranian Red Crescent Medical Journal, 19, e15730. https://doi.org/10.5812/ircmj.15730

[16] Moran, O. and Philip, M. (2003) Leptin “Obesity”, Obesity, Diabetes and Other Peripheral Effects a Review. Pediatric Diabetes, 2, 101-109. https://doi.org/10.1034/j.1399-5448.2003.00017.x 